\title{
Testicular torsion and weather conditions: analysis of 21,289 cases in Brazil
}

Fernando Korkes, Paulo Roberto dos Anjos Cabral, Caio Dal Moro Alves, Mariana Lorenzi Savioli, Antonio Carlos Lima Pompeo

Division of Urology, ABC Medical School

\section{ABSTRACT}

Purpose: The hypothesis of association between testicular torsion and hyperactive cremasteric reflex, worsened by cold weather, has not been proved. Thirteen studies in the literature evaluated this issue, with inconclusive results. The aim of the present study was to evaluate the seasonality of testicular torsion in a large subset of patients surgically treated in Brazil, and additionally to estimate the incidence of testicular torsion.

Materials and Methods: Brazilian Public Health System Database was assessed from 1992-2010 to evaluate hospital admissions associated with treatment of testicular torsion. Average monthly temperature between 1992-2010 was calculated for each region.

Results: We identified 21,289 hospital admissions for treatment of testicular torsion. There was a higher number of testicular torsions during colder months ( $p$ $=0.002$ ). To estimate the incidence of testicular torsion, we have related our findings to data from the last Brazilian census (2010). In 2010, testicular torsion occurred in 1.4:100,000 men in Brazil.

Conclusions: Testicular torsion occurred at an annual incidence of approximately 1.4:100,000 men in Brazil in 2010. Seasonal variations do occur, with a significant increase of events during winter. Our findings support the theory of etiological role of cold weather to the occurrence of testicular torsion. Strategies to prevent these events can be based on these findings.

\section{ARTICLE INFO}

\section{Key words:}

spermatic cord torsion; testis; male; child; climate; seasons; Brazil

Int Braz J Urol. 2012; 38: 222-9

Submitted for publication:

July 20, 2011

Accepted after revision: January 06, 2012

\section{INTRODUCTION}

Testicular torsion is an infrequent event characterized by testicular rotation around its cord. It causes interruption of blood supply and necrosis if treatment is delayed. It can occur at any age although it is more common during childhood and adolescence, and incidence slowly decreases with age. Testicular torsion normally presents as sudden severe pain followed by testicular swelling and reddening of the scrotal skin. Other symptoms as abdominal pain, nausea and vomiting may occur. Surgical treatment includes orchidopexy or orchidectomy, according to testicle viability (1). Even though diagnosis and treatment are straightforward in most cases of testicular torsion, etiology is still controversial (1). The theory of hyperactive cremasteric reflex, which supposedly could be worsened by cold weather, has not yet been proved (2). Thirteen studies in the literature have evaluated seasonality of testicular torsion, with a total of 4,659 
patients evaluated (3-15). Different conclusions were drawn from these studies regarding the validity of the hyperactive cremasteric reflex theory. The aim of the present study was to evaluate the seasonality of testicular torsion in a large subset of patients surgically treated from 1992 to 2010 in Brazil, and additionally to estimate the incidence of testicular torsion in this large population series.

\section{MATERIALS AND METHODS}

We used the Brazilian Public Health System Information Database (DATASUS) from 1992 to 2010 as the primary data source for our study (16). DATASUS represents the primary effort of the federal government to collect data from the national health system. This database includes information from all public health hospitals throughout the country. Using the DATASUS public database between 1992 and 2010, hospital admissions associated with surgical treatment of testicular torsion have been searched. A total of 21,289 men admitted to public hospitals who underwent surgical treatment of testicular torsion were identified.

Men were divided according to month of diagnosis/treatment, year and region of the country. Brazil is divided in five main regions: South, Southeast, Central-West, Northeast and North. These regions have very distinctive climate among each other, being the Southern temperatures colder than the Northern. One index city of each region was chosen, and average monthly temperature between 1992 and 2010 was calculated for each city based on data collected from historical weather data. Demographic data from the Brazilian population were obtained from the last national census, realized in 2010 (17).

We described trends in the rate of testicular torsion and identified relations between weather temperature and incidence of testicular torsion in Brazil and its distinctive regions from 1992 to 2010. Statistical analysis was performed using SPSS 13.0 (SPSS for Mac OS X, SPSS, Inc., Chicago, Illinois). Groups were compared with Pearson's chi-square test and ANOVA. Statistical significance was determined at $\mathrm{p}<0.05$.

\section{RESULTS}

From 1992 to 2010 we identified 21,289 hospital admissions for surgical treatment of testicular torsion. Patients were distributed according to month and year of incidence and geographic region of the country - North, Northeast, Central-West, South and Southeast regions of Brazil (Table-1). These data were also corrected according to total population of each region. Statistical analysis was performed between regions, and there were similar rates of testicular torsion $(\mathrm{p}=0.38)$.

Table 1 - Distribution of men surgically treated for testicular torsion in each region of the country (1992-2010) and its male population (2010), Brazil.

\begin{tabular}{|c|c|c|c|c|c|}
\hline & $n$ & $\%$ of total cases & $\begin{array}{l}\text { Male Population } \\
\text { (millions) }\end{array}$ & $\begin{array}{c}\% \text { of Male Brazilian } \\
\text { population }\end{array}$ & $p$ \\
\hline South & 3,340 & 15.69 & 13.44 & 14.38 & \\
\hline Southeast & 8,565 & 40.23 & 39.08 & 41.83 & \\
\hline Central-West & 1,368 & 6.43 & 6.98 & 7.47 & \\
\hline Northeast & 6,606 & 31.03 & 25.91 & 27.74 & \\
\hline North & 1,410 & 6.62 & 8.00 & 8.57 & \\
\hline TOTAL & 21,289 & 100.00 & 93.41 & 100.00 & 0.38 \\
\hline
\end{tabular}


Variation between the mean hottest (February) and mean coldest (July) months in Brazil from 1992 to 2010 was $4.38^{\circ} \mathrm{C}$ (ranged from $20.5^{\circ} \mathrm{C}$ to $24.9^{\circ} \mathrm{C}$ ). Temperature variation was higher in the southern vs. northern regions $\left(6.5^{\circ} \mathrm{C}\right.$ vs. $3.1^{\circ} \mathrm{C}$, $\mathrm{p}<0.0001)$. There was a significant increment in number of testicular torsion operated during colder months (Figure- $1 \mathrm{~F}, \mathrm{p}=0.002$ ). When considering the distinctive geographic regions of Brazil, there were significant differences between incidences of testicular torsion in average hottest vs. coldest months of the year in both the northern ( $p$ $<0.001$, Pearson $=18.7, \mathrm{OR}=1.1)$ and southern $(\mathrm{p}$ $<0.0001$, Pearson $=160.3$, OR $=1.4$ ) regions, but differences were more significant in the South and Southeast regions (Figures 1D-E).

When historical series were evaluated according to number of cases per year in each geographic region, there was a trend toward re- duction of incidence of men with testicular torsions operated at the public health system in the Southeast region of Brazil (Figure-2).

To estimate incidence of testicular torsion, we have related our findings to data from the last Brazilian census. In 2010, there were $65,384,893$ men in the Brazilian public health system. Average number of testicular torsions in Brazil was of 1,120/year (from 1992 to 2010) and of 920 in 2010, representing an overall incidence of approximately 1.4 torsions/100,000 men in 2010.

\section{DISCUSSION}

Intravaginal torsion of the spermatic cord is an emergency condition, with risk of irreversible ischemic injury to testicular function if not promptly treated. It is caused by the torsion of

Figure $1(A-F)$. A) Distribution of testicular torsion cases in Brazilian public health system from 1992-2010 according to month of the year, average monthly temperature $\left({ }^{\circ} \mathrm{C}\right)$ and geographic regions $(A-E)$; Brazil $(F)$.
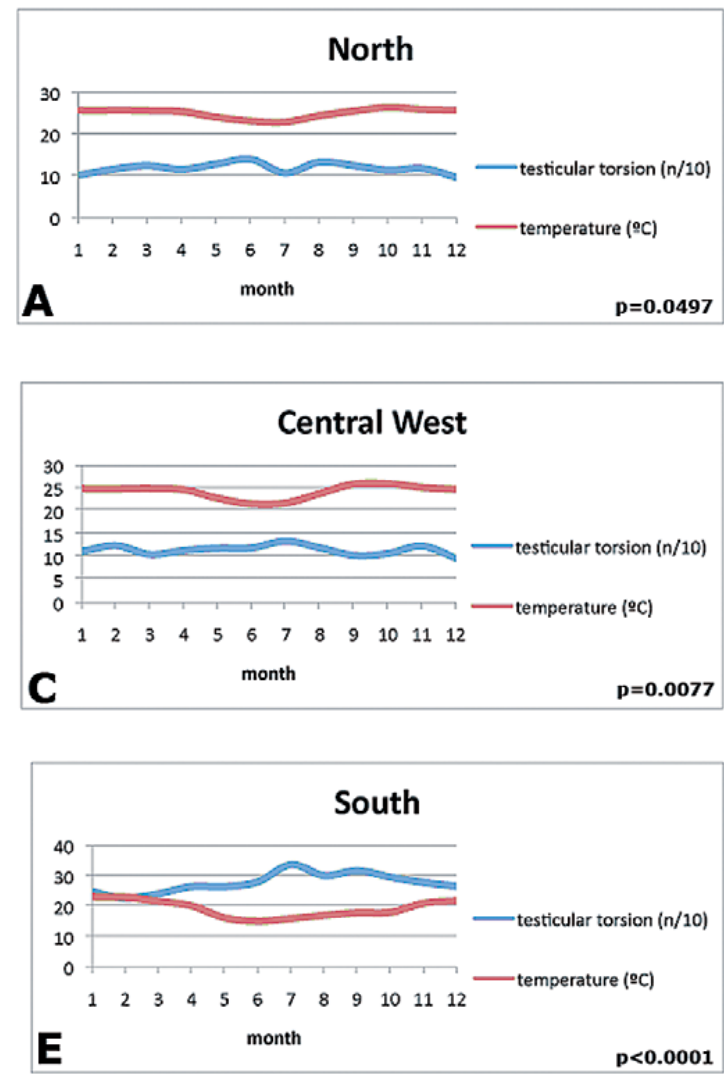
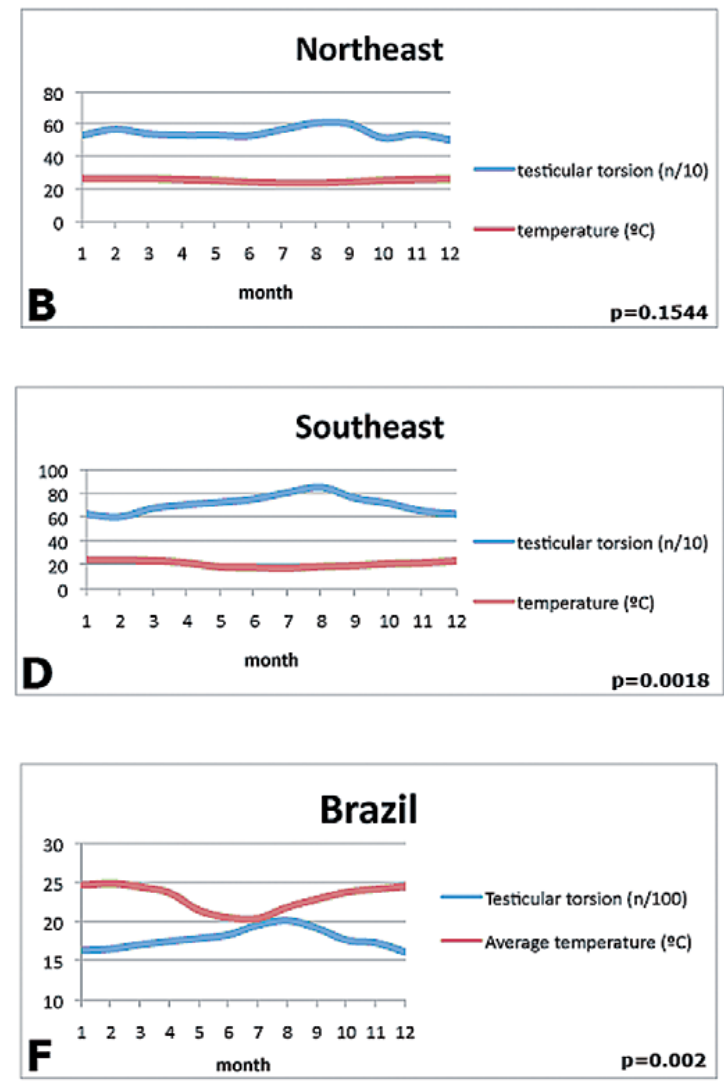
Figure 2 - Historic series of testicular torsion in the public health system in Brazil, 1992-2010 (geographic regions).

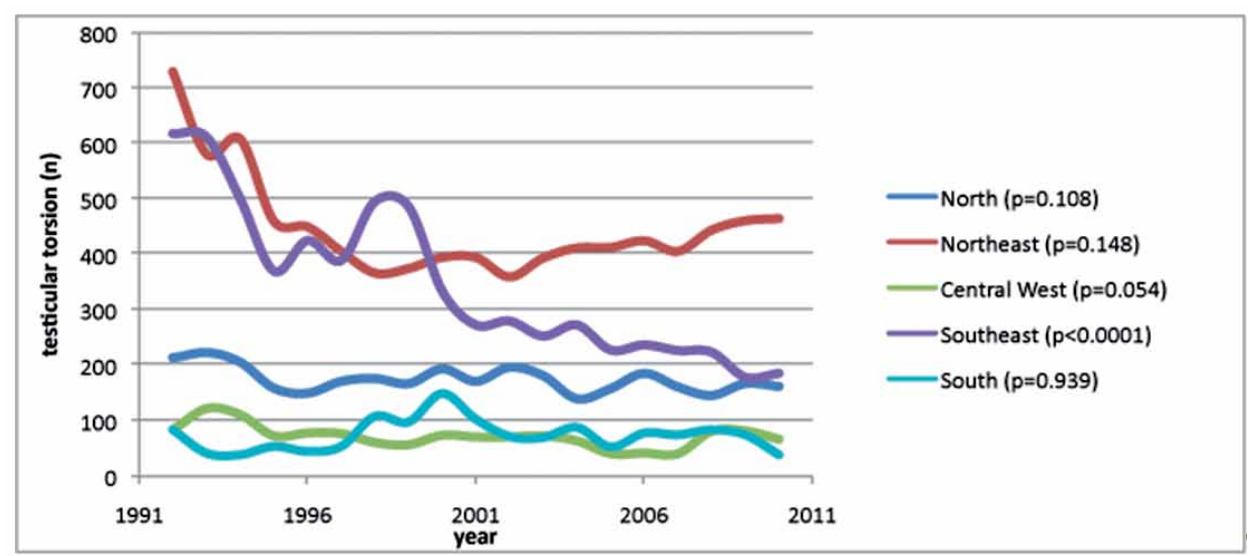

the spermatic cord within the space of the tunica vaginalis. It may result from the lack of normal fixation of an appropriate portion of the testis and epididymis to the fascial and muscular layers that surround the cord within the scrotum. The free space between visceral and parietal layers of the tunica vaginalis can extend proximally up to the cord for a variable distance. When it extends to the spermatic cord, an abnormality denominated "bell-clapper deformity" is characterized, leading to an over-mobility of the testis that hangs freely within the tunical space $(1,18,19)$. However, the presence of bell-clapper abnormality is only a predisposing factor to testicular torsion, since not all men with such deformity develop testicular torsion (19). Other risk factors associated with testicular torsion include trauma, exercise and hyperactive cremasteric reflex.

The association between cold weather and cremasteric reflex is well established in vitro and the theory of hyperactive cremasteric reflex in the setting of cold weather is postulated as another predisposing factor to testicular torsion (2). There are thirteen studies in the medical literature evaluating this issue, with distinctive conclusions (Table-2) (3-15). To test the hypothesis of association between cold weather and testicular torsion, we have evaluated this large series of men with testicular torsion.

Our study has some important findings. First, there was a clear increment in hospital ad- missions to surgical treatment of testicular torsion during the coldest months of the year in Brazil. In the Southeast of Brazil were climatic amplitude was higher and more precise data available, this association was even more evident and in the coldest months of the year there were significant increments in the occurrence of testicular torsion. These findings corroborate to hypothesize an association between testicular torsion and cold weather. Previous reports on the seasonality of testicular torsion have been conflicting. Shukla et al. were the first authors to hypothesize an association between cold weather and testicular torsion in 1982 (3). Since than, a total of 9 studies have found a positive association between low ambient temperature and testicular torsion (3-11) whereas 4 did not (12-15). All studies that found a positive association were conduced in cold regions or regions with high temperature amplitude. On the other hand, there are four studies that have not observed seasonal variation of testicular torsion. In a series of 2,876 men, Cost et al. have not observed seasonal variations of testicular torsion (15). However, this study included men from all across the United States, a country with very different weather conditions, without distinctions according to regions' temperature (15). Williams et al. did not find a statistically significant association but a clear trend towards seasonality was reported by the authors (14). Preshaw found similar rates of testicular torsion throughout the year among 272 men evalu- 
Table 2 - Studies evaluating the association between seasonality and testicular torsion (3-15).

\begin{tabular}{|c|c|c|c|c|c|}
\hline Author & Year & $n$ & Country & $\begin{array}{l}\text { Statistic association with } \\
\text { seasonality? }\end{array}$ & $\begin{array}{l}\text { Total n: } \\
4,659\end{array}$ \\
\hline Shukla et al. (3) & 1982 & 46 & Ireland & yes & \\
\hline Mabogunje (4) & 1986 & 131 & Nigeria & yes & \\
\hline Anderson and Williamson (5) & 1988 & 624 & England & yes & \\
\hline Hoshino et al. (6) & 1993 & 39 & Japan & yes & \\
\hline Ugwu et al. (7) & 2003 & 57 & Nigeria & yes & \\
\hline Al-Hunayan et al. (8) & 2004 & 75 & Kuwait & yes & \\
\hline Srinivasan et al. (9) & 2007 & 58 & USA & yes & \\
\hline Lyronis et al. (10) & 2009 & 39 & Greece & yes & \\
\hline \multirow[t]{2}{*}{ Molokwu et al. (11) } & 2011 & 173 & Scotland & yes & \\
\hline & & & & TOTAL & 1,242 \\
\hline Driscoll et al. (12) & 1983 & 134 & Scotland & No & \\
\hline Preshaw (13) & 1984 & 272 & Canada & No & \\
\hline Williams et al. (14) & 2003 & 135 & USA & No & \\
\hline \multirow[t]{2}{*}{ Cost et al. (15) } & 2011 & 2,876 & USA & No & \\
\hline & & & & TOTAL & 3,417 \\
\hline
\end{tabular}

ated (13). Interestingly, this study was conduced in Calgary, Canada, where there is a cold and dry weather, but there is a long cold season, greater extremes of daily temperature and little climatic amplitude throughout the year.

Previous authors have raised the relevance of indoor/outdoor temperature, reporting that nearly $55 \%$ of testicular torsions occurred indoors (12). In this scenario, in places with extreme weather conditions where indoor/outdoor temperatures tend to differ more, it might be difficult to evaluate the association between testicular torsion and climatic conditions. In Brazil, particularly in the Southeast region, climatic conditions vary, but temperatures are normally agreeable. In this setting, heaters are not commonly available, and during winter indoor and outdoor temperatures are more similar to each other. Further studies evaluating a large number of cases in a smaller region, with more constant climatic variations might bring more information about this issue. It seems that not only temperature, but also other climatic factors as humidity might also play an important role (4).

We could estimate the incidence of testicular torsion in a large population series. From 1992 to 2010, annual incidences ranged from 896 to 1715 cases (mean \pm standard deviation $=1120$ \pm 232 cases/year). Incidence in Brazil during 2010 could be estimated of 1.4 torsions/100.000 men. This incidence is lower than estimated for colder countries of 27-48 torsions/ 100.000 men $(5,20)$ and even in hotter middle-east countries, with incidence of 7.9 torsions/100.000 men estimated (8). We are not sure about the factors associated with these remarkable low rates of testicular torsion in Brazil. Possible explanations could be the underreporting of cases, demographic characteristics or possibly the hot weather. Maybe colder countries have higher incidences of testicular torsion $(5,20)$.

There was also a trend toward reduction in the number of annual cases in the Southeast re- 
gion of Brazil when comparing the number of annual cases in the last decades. However this data might be biased as Brazil has been experiencing remarkable development in the last decades, leading to an increase in access to private health system (17). The same bias can be related to the observation of a difference of the annual incidence of testicular torsion in each region of the country corrected by its population (Table-1). Economic and social characteristics of the population within the five regions of Brazil are very distinctive, and access to private health services vary. Therefore, no further conclusions can be withdrawn from these data.

Our study has several limitations. DATASUS registries do not provide clinical information, limiting further analysis. In addition maybe some patients treated surgically with an initial diagnosis of testicular torsion could have other conditions and some information might be incorrect, since we could not exclude: 1-) men who underwent surgery and intraoperative diagnosis was other than testicular torsion; 2-) men discharged with scrotal pain and with a missed diagnosis of testicular torsion. However, we believe that; 1-) These false positive and false negative cases might compensate each other; 2-) Since we are mainly evaluating seasonal variations, these possible biases might not vary according to weather conditions. However these biases could impair our incidence calculi. Nevertheless, as testicular torsion incidence had not been previously estimated in any tropical country, we believe that, even though not perfect, our data are very important.

Furthermore, only public health system data can be assessed, and this information evaluates only $70 \%$ of the Brazilian population. Besides, only average temperatures of a determined month during the study period were considered, and not the exact temperatures in the moments that each torsion occurred. However, to the best of our knowledge this is the larger epidemiologic study about testicular torsion, and we believe these findings can help to explain factors associated with testicular torsion.

\section{CONCLUSIONS}

In conclusion, testicular torsion occurred at an annual incidence of 1.4:100,000 men in Brazil in 2010. Seasonal variations do occur, with a significant increase in incident cases during colder months. Our findings support the theory of etiological role of cold weather in intravaginal torsion of testis. Maybe strategies to prevent these events can be thought in a near future based on these findings.

\section{CONFLICT OF INTEREST}

None declared.

\section{REFERENCES}

1. Schneck FX, Bellinger MF: Abnormalities of the testes and scrotum and their surgical management. In: Walsh PC, Retik $A B$, Vaughan ED, Wein AJ, (ed.), Campbell's Urology. 8th edition. Philadelphia: WB Saunders, 2002. Chapter 67, p. 2353-94.

2. Bingöl-Koloğlu $M$, Sara $Y$, Tanyel FC, Onur R, Büyükpamukçu N, Hiçsönmez A: Contractility and electrophysiological parameters of cremaster muscles of boys with a hernia or undescended testis. J Pediatr Surg. 1998; 33: 1490-4.

3. Shukla RB, Kelly DG, Daly L, Guiney EJ: Association of cold weather with testicular torsion. Br Med J (Clin Res Ed). 1982; 285: 1459-60.

4. Mabogunje $\mathrm{OA}$ : Testicular torsion and low relative humidity in a tropical country. Br Med J (Clin Res Ed). 1986; 292: 363-4.

5. Anderson JB, Williamson RC: Testicular torsion in Bristol: a 25-year review. Br J Surg. 1988; 75: 988-92.

6. Hoshino $\mathrm{H}$, Abe $\mathrm{T}$, Watanabe $\mathrm{H}$, Katsuoka $\mathrm{Y}$, Kawamura N: Correlation between atmospheric temperature and testicular torsion. Hinyokika Kiyo. 1993; 39: 1031-3; discussion 1033-4.

7. Ugwu BT, Dakum NK, Yiltok SJ, Mbah N, Legbo JN, Uba AF et al.: Testicular torsion on the Jos Plateau. West Afr J Med. 2003; 22: 120-3.

8. Al-Hunayan AA, Hanafy AM, Kehinde EO, Al-Awadi KA, Ali YM, Al-Twheed AR et al.: Testicular torsion: a perspective from the Middle East. Med Princ Pract. 2004; 13: 255-9. 
9. Srinivasan AK, Freyle J, Gitlin JS, Palmer LS: Climatic conditions and the risk of testicular torsion in adolescent males. J Urol. 2007; 178: 2585-8; discussion 2588.

10. Lyronis ID, Ploumis N, Vlahakis I, Charissis G: Acute scrotum-etiology, clinical presentation and seasonal variation. Indian J Pediatr. 2009; 76: 407-10.

11. Molokwu CN, Somani BK, Goodman CM: Outcomes of scrotal exploration for acute scrotal pain suspicious of testicular torsion: a consecutive case series of 173 patients BJU Int. 2011; 107: 990-3.

12. Driscoll PA, Brume J, Meehan SE: Cold weather and testicular torsion. Br Med J (Clin Res Ed). 1983; 286: 1751.

13. Preshaw RM: Seasonal frequency of testicular torsion. Can J Surg. 1984; 27: 404-5.

14. Williams CR, Heaven KJ, Joseph DB: Testicular torsion: is there a seasonal predilection for occurrence? Urology. 2003; 61: 638-41; discussion 641.

15. Cost NG, Bush NC, Barber TD, Huang R, Baker LA: Pediatric testicular torsion: demographics of national orchiopexy versus orchiectomy rates. J Urol. 2011; 185 Suppl): 2459-63.
16. Ministry of health (Brazil), SUS Department of Informatics (DATASUS) [Internet]. [cited 2011 Dec 3]. Available from: http://www.datasus.gov.br

17. Brazilian Institute of Geography and Statistics (IBGE) [Internet]. Available from: http://www.ibge.gov.br/home/default.php

18. Favorito LA, Cavalcante AG, Costa WS: Anatomic aspects of epididymis and tunica vaginalis in patients with testicular torsion. Int Braz J Urol. 2004; 30: 420-4.

19. Caesar RE, Kaplan GW: Incidence of the bell-clapper deformity in an autopsy series. Urology. 1994; 44: 114-6.

20. Barada JH, Weingarten JL, Cromie WJ: Testicular salvage and age-related delay in the presentation of testicular torsion. J Urol. 1989; 142: 746-8.

\footnotetext{
Correspondence address:

Dr. Fernando Korkes Rua Pirapora, 167

São Paulo, SP, 04008-060, Brazil Telephone: +55 11 3884-2233 E-mail: fkorkes@terra.com.br
}

\section{EDITORIAL COMIMENT}

Given the limited and relatively contemporary literature on the issue, although with important limitations (once well recognized), the study of Korkes et al. is an important epidemiological study regarding the suspicion of testicular torsion related to weather conditions based on DATASUS and IBGE, including the databases restrictions. The rational was previously proposed in the literature since 1982 (1) and observed for the first time in 1986 in a tropical country (2).

While the authors present the largest study in the literature, there is no demographic data about studied patients and neither diagnosis confirmation. In studies of acute scrotum where surgical exploration of the testes was performed without a preoperative ultrasound evaluation, true testicular torsion was found in only 33\% of cases (3). Among the countless potential biases intrinsic to the study design, it can be the case of analyzed events considering the Brazilian public health system limited circumstances.

The practice of medicine contains countless examples of elegant medical theories that contradict the best available evidence; to increase the critical reasoning abilities of readers of the urological literature and to raise the level of evidence are fundamental tasks (4).

Future well-controlled and prospectively designed studies are warranted to confirm the hypothesis originally proposed by Shukla et al. in 1982 (1) and to expand the knowledge on the issue, recognizing and balancing important potentially confounding effects, including other climatic factors as humidity, indoor/outdoor ambience as well as detailed factors related to patients as cultural and surgical practices. 


\section{REFERENCES}

1. Shukla RB, Kelly DG, Daly L, Guiney EJ: Association of cold weather with testicular torsion. Br Med J (Clin Res Ed). 1982; 285(6353): 1459-60.

2. Mabogunje $\mathrm{OA}$ : Testicular torsion and low relative humidity in a tropical country. Br Med J (Clin Res Ed). 1986; 292: 363-4.
3. Gunther P, Schenk JP, Wunsch R, Holland-Cunz S, Kessler $\mathrm{U}$, Troger J, et al.: Acute testicular torsion in children: the role of sonography in the diagnostic workup. Eur Radiol. 2006; 16: 2527-32.

4. Oliveira Reis L: The bedrock of daily practice on urology and evidence based medicine. Actas Urol Esp. 2009; 33: 1054-6.

Dr. Leonardo Oliveira Reis Department of Surgery (Urology) State University of Campinas - UNICAMP Hospital das Clinicas UNICAMP 20 andar, A2 - sala 108

R. Vital Brazil - 250

Cidade universitária Zeferino Vaz,

Distrito de Barão de Geraldo Campinas, SP, Brasil

E-mail: reisleo@unicamp.br 